\title{
Informação e conhecimento na economia solidária
}

\author{
Angel Freddy Godoy Viera \\ Fabricio Foresti \\ Universidad Federal de Santa Catarina - UFSC, Brasil
}

Viviane da Rosa

Secretaria de Estado da Assistência Social, Trabalho e Habitação, Governo de Santa Catarina, Brasil

\section{ARTICLE}

\section{Resumo}

Objetivo. O estudo busca identificar como a questão da informação e do conhecimento é abordada em Economia Solidária (ES) de forma a identificar as necessidades e problemas relacionados.

Método. Para alcançar os objetivos propostos foi realizada pesquisa quantitativa bibliográfica com amostra composta por 60 artigos revisados por pares recuperados na base SciELO (Scientific Electronic Library Online) com as palavras-chave Economia Solidária no título. A pesquisa relaciona as frequências dos termos informação e conhecimento com 14 classes de interesse e objeto de estudo da Ciência da Informação.

Resultados. Foram identificados os autores que mais citam a informação e o conhecimento em suas publicações, bem como os períodicos mais relevantes para a área e os problemas mais recorrentes em relação à informação e ao conhecimento na Economia Solidária, em conformidade com a amostra e os procedimentos metodológicos. Ao final é apresentada tabela que aponta formas de atuação possíveis pelos profissionais da informação frente à Economia Solidária. Conclusões. Conclui que a informação e o conhecimento são fundamentais para a Economia Solidária, mas que muitas carências são básicas e que o tipo de informação mais relevante para a Economia Solidária é a informação para a tomada de decisão coletiva.

Palavras-chave

Economia solidária ; Informação ; Conhecimento

\section{Information and knowledge in solidary economy}

\begin{abstract}
Objective. The objectives of this study are identify how the issue of information and knowledge are discussed on Solidarity Economy and identify information needs and related problems.

Method. Bibliographic quantitative research which studies the issue of information and knowledge in the Solidarity Economy. The research sample consists of 60 peer reviewed papers from a free online source (SciELO - Scientific Electronic Library Online) with the keywords Solidarity Economy in the title. The survey lists the frequencies of the terms information and knowledge with 14 classes of interest of Information Science.

Results. The authors who more cite the information and knowledge were identified, as well the most recurring problems in relation to information and knowledge in the Solidarity Economy. Is presented table that shows possible forms of activity by information professionals across the Solidarity Economy.

Conclusions. Concludes that information and knowledge are fundamental to the Solidarity Economy, but that many needs are basic and the most relevant type of information for Solidarity Economy is information for collective decision-making.
\end{abstract}




\section{Introdução}

A Economia Solidária (ES) é uma tendência contemporânea da economia que está organizada em todo o mundo, independente dos níveis de desenvolvimento econômico. Suas iniciativas estão diretamente ligadas à sustentabilidade e ao meio ambiente ao passo que trata-se de um imperativo do desenvolvimento sustentável, tema de grande importância na sociedade contemporânea. Este diagnóstico inicial abre portas para que a 0 conhecimento da Ciência da Informação possa contribuir com esta tendência da economia que promove o comércio justo e solidário, a compra consciente e a inclusão de setores sociais anteriormente marginalizados

O conceito de ES nasce segundo Azambuja (2009, p. 310) "de um esforço em compreender a lógica de determinadas iniciativas econômicas" emergentes no final do século XX. De acordo com o Portal do Ministério do Trabalho e Emprego (MTE) (BRASIL, 2014) a ES "é um jeito diferente de produzir, vender, comprar e trocar o que é preciso para viver sem explorar os outros" e "sem destruir" o meio ambiente, um lugar onde consumidor e produtor pensam "no bem de todos e no próprio bem". Ainda segundo o MTE a ES "vem se apresentando" como uma "inovadora alternativa de geração de trabalho" além de "uma resposta a favor da inclusão social" que envolve uma grande variedade de "práticas econômicas e sociais organizadas" como cooperativas, associações, clubes de troca, empresas autogestionárias, redes de cooperação, etc. que produzem algum bem ou prestam algum serviço, desde finanças solidárias até o comércio justo e consumo solidário, finalidade de todo o processo.

A Portaria n. 2060/2014 do MTE (BRASIL, 2015) define ES como "atividades econômicas" relacionadas à "produção de bens e serviços", de distribuição, de consumo, de finanças, solidárias, coletivas e "autogestionárias". A ES funciona através dos Empreendimentos Econômicos Solidários (EES) definidos pela mesma portaria como organizações de "caráter associativo" que desenvolvem "atividades econômicas" onde os membros exercem "democraticamente a gestão das atividades e a alocação dos resultados". São organizações:

Coletivas [...] suprafamiliares, singulares e complexas [...] como: associações, cooperativas, empresas autogestionárias, grupos de produção, clubes de trocas, redes etc.; cujos participantes ou sócios (as) são trabalhadores (as) dos meios urbano e rural que exercem coletivamente a gestão das atividades, assim como a alocação dos resultados; permanentes [...] que disponham ou não de registro legal, prevalecendo à existência real, e que realizam atividades econômicas de produção de bens, de prestação de serviços, de fundos de crédito [...] de comercialização [...] e de consumo solidário. (KUYVEN; KAPPES, 2013, p. 8).

O desenvolvimento solidário é um processo que incentiva a criação de modos de produção alternativos para a sustentabilidade do desenvolvimento econômico, a preservação da natureza e a redistribuição dos lucros e do crescimento em prol dos excluídos da produção social, ou seja, o desenvolvimento sustentável cria outras relações de produção (SINGER, 2004, p. 7) e os seus objetivos vão além do lucro e do capital, em favor da sociedade e não apenas dos interesses empresariais.

Os EES envolvem grande número de organizações e atividades distintas. O II Mapeamento da Economia Solidária na Região Sul (KUYVEN; KAPPES, 2013, p. 12) mostra que no Sul do Brasil a maior parte dos EES, quanto à forma de organização, são informais (44\%), associações (36\%) cooperativas (19\%) e sociedades mercantis (1\%). Também mostra que $41 \%$ dos EES são rurais e $42 \%$ urbanos e que mais de $50 \%$ dos sócios enxergam os EES como fonte de renda complementar. Essas características da ES demandam pesquisa e abordagens interdisciplinares para lidar com a questão da informação e do conhecimento, especialmente quanto à informalidade dos EES, problema com o qual a Portaria 2060/2014 do MTE tenta amenizar com o cadastro nacional.

Assim, os objetivos deste estudo são conhecer como os autores da área de ES abordam a temática da informação e do conhecimento e identificar quais os problemas reais de informação e conhecimento na ES. Uma vez que os problemas e carências acerca da informação e do conhecimento são identificados, a Ciência da Informação pode traçar estratégias para contribuir com a ES e exercer a sua responsabilidade social.

\section{Economia Solidária e Ciência da Informação}

A Ciência da Informação possui uma responsabilidade e uma função social (FREIRE, 2002) e a pesquisa na área compreende um diversificado campo do conhecimento que estuda, entre outros fenômenos, a comunicação, os usuários e as relações entre os homens e as máquinas quanto ao acesso à informação e ao conhecimento. (GUINCHAT; MENOU, 1994, p. 526). A informação fornece o conhecimento para a ação social, seja de grupos ou indivíduos. (FREIRE, 2002, p. 11). Mas apesar do discurso de responsabilidade social da Ciência da Informação e das suas contribuições com a sustentabilidade e a inclusão social, Almeida Jr. (1997, p. 
51) verifica uma praxe de não se envolver em movimentos sociais e questiona a neutralidade, a utilidade e os objetivos das bibliotecas. Para Almeida Jr. (1997, p. 54) a biblioteca deve atender com prioridade a maior parcela da população ou os "carentes de informação" de tal forma que a "população comece a reconhecer no bibliotecário, um profissional útil socialmente e a biblioteca como uma instituição necessária". O autor ainda expõe questões como a democratização da informação, centros de documentação popular, a relação da biblioteca com a comunidade, etc., mas um capítulo em especial chama a atenção, em que Almeida Jr. (1997, p. 107) reconhece que os bibliotecários possuem um "desconhecimento da real função social' de sua profissão, não se veem como agentes de transformação social, fato que fica evidenciado pela pequena participação das associações de bibliotecários em movimentos sociais.

Em pesquisa realizada sobre a percepção dos profissionais da informação sobre sua responsabilidade social, Fonseca e Garcia (2009, p. 9) mostram que muitos Bibliotecários conceituam responsabilidade social como "assistencialismo", ações relacionadas à doação de dinheiro para desenvolvimento de "atividades de grande mérito social', a responsabilidade social ainda é vista por muitos profissionais como uma forma de promover o desenvolvimento e as mudanças sociais sem a participação do Estado; outra visão errônea do "conceito" de responsabilidade social por parte dos profissionais da informação está ligada à "disseminação da informação", as autoras questionam essa possibilidade ao passo que disseminar informação faz parte da profissão da informação, além de não ser a única responsabilidade do profissional da informação. Segundo as autoras, o profissional da informação possui uma responsabilidade "ampla e envolve usuários, acervos, empregados, meio ambiente, o governo e a sociedade".

Assim, é mister que o profissional e a Ciência da Informação colaborem efetivamente com a inclusão social, mas para entender como a Ciência da Informação pode contribuir com a ES, é preciso entender e definir com clareza os conceitos relacionados, os problemas apontados pelos autores da área de ES e propor metodologias que auxiliem o movimento econômico solidário.

A informação é peça chave nos EES como em todos os empreendimentos econômicos na sociedade da informação e do conhecimento. A Aliança Cooperativa Internacional (ICA, 2015) cita dentre seus princípios, a "educação, formação e informação", também cita como dever das cooperativas promover a educação e a formação dos seus membros. Nesse universo informacional, a informação sobre a própria ES é igualmente importante, ela fornece subsídios ao planejamento de curto, médio e longo prazo às instituições públicas e privadas e também aos próprios EES. Com esse intuito, foi desenvolvido o Sistema de Informações em Economia Solidária (SIES), que de segundo o MTE (BRASIL, 2014b) trata-se de uma "iniciativa pioneira para a identificação e caracterização" dos EES e entidades de apoio. Dentre os objetivos do SIES está a criação de uma base de dados brasileira de informação sobre a ES (KUYVEN; KAPPES, 2013, p. 6). O SIES de fato criou uma plataforma que permite acompanhar as especificidades da ES no Brasil, plataforma que subsidia as políticas públicas relacionadas ao tema da ES (ARRUDA, 2013, p. 751). As informações sobre a ES são especialmente "valiosas" para a "análise de políticas públicas" sustentam Nagem e Silva (2013, p. 165), segundo os autores, a Lei de Diretrizes Orçamentárias reforçou a importância da informação na ES e destina recursos ao SIES.

A informação oriunda dos eventos sobre ES é especialmente importante segundo Silva e Oliveira (2009, p. 65), é uma informação que aproxima os trabalhadores e organizações ligadas a ES, os eventos abrem um "amplo leque de relações com os diversos atores" e também oportunidades de aquisição de "recursos importantes" para a sustentação dos empreendimentos solidários, tais como "informações, reconhecimento" e "capacitação", entre outros. É através dos eventos (seminários, assembleias, fóruns, congressos, etc.) que os trabalhadores tem a oportunidade de adquirir conhecimento novo e manifestar sua opinião sobre os mais diversos assuntos, além de poder entrar em contato com seus pares, discutir e buscar soluções conjuntas aos problemas enfrentados. De fato, existe um tipo de capital social "entendido como recursos materiais e/ou simbólicos" formado pelas "relações" e pelas possiblidades de acesso a recursos materiais e simbólicos apontam Silva e Oliveira (2009, p. 61). Dentre esses recursos estão a informação, as bibliotecas, os arquivos, as tecnologias da informação, a internet, as técnicas e métodos de gestão, entre outros. A questão é como tornar esses recursos acessíveis ao movimento econômico solidário. Depende inicialmente, entre outros fatores, da postura dos profissionais e das unidades da informação, de abrir as suas portas para a ES, de realizar um chamamento, de ceder o espaço para uso e principalmente, de exercer a sua responsabilidade social.

É mister que a ES utilize a informação e o conhecimento como insumo tão fundamental como as matérias primas que são confeccionados seus produtos finais. Segundo Araújo, Pinho e Córdula (2015) "a informação" é "um artefato que norteia os caminhos traçados por civilizações”. Para Le Coadic (1996, p. 10-11) a informação é um ciclo que envolve a "construção", a "comunicação" e o "uso" da informação, em que cada um desses elementos se influenciam reciprocamente. A ES precisa pensar em um fluxo de informação que estabeleça a 
construção dessa informação solidária em uníssono dentro da ES, para então criar estratégias de disseminação e uso dessa informação pela sociedade e pela própria ES. A informação também é "conhecimento comunicado" e protagonista na sociedade hodierna apontam Capurro e Hjorland (2007, p. 149). Segundo os autores é "lugar comum considerar-se a informação como condição básica para o desenvolvimento econômico" em conjunto com o "capital, o trabalho e a matéria prima". Segundo Saracevic (1999, p. 1062) atualmente a informação é mercadoria valorizada e se tornou um bom negócio, e a Ciência da Informação é "parte importante dos esforços" para lidar não apenas com o enorme volume de informação mas especialmente por estudar as pessoas que necessitam utilizar e "interagir" com a informação para sua "subsistência" e resolução de problemas. Hoje a Ciência da Informação amplia seus limites e apresenta novas formas de "olhar os fenômenos informacionais" e observar as "dimensões históricas, econômicas, políticas e socioculturais" apontam Gandra e Duarte (2012, p. 13). A dimensão hodierna da informação e os novos olhares da Ciência da Informação se cruzam com a tendência contemporânea de uma economia mais justa e sustentável.

A ES ao desafiar os valores do capital pode ser entendida como uma espécie de contra poder. Segundo Castells (2013, p. 14) o contra poder é a "capacidade de os atores sociais desafiarem o poder embutido nas instituições da sociedade com o objetivo de reivindicar a representação de seus próprios valores e interesses". Segundo o autor a "luta fundamental pelo poder" está ligada à "construção de significado" e o ambiente informacional transfigura não apenas as formas de "construção de significado", mas também influenciam o estabelecimento de novas "relações de poder". A ES deve travar uma luta quanto à construção de significado entre os consumidores e fazer com que a sociedade conheça seus valores para que o consumo solidário seja praticado e respeitado. É somente com informação e conhecimento novo que os consumidores podem mudar seu paradigma de consumo tão arraigado aos antigos valores do capital e do lucro desenfreado, que não respeita a natureza e os homens. A ES para tanto precisa tirar proveito da Internet, das redes sociais, dos mecanismos de busca, de parcerias globais, afinal, a rede abre uma ampla possibilidade de disseminação da informação solidária, além de unir todos os seres solidários. Ao mesmo tempo a ES deve agregar valor aos seus produtos através da informação e do conhecimento e habilitar seus membros a ampliarem sua capacidade de processamento, de informação.

Quando se discute os conceitos de informação é importante destacar a afirmação de Capurro e Hjorland (2007, p. 160) de que atualmente grande parte das disciplinas científicas utilizam conceitos de "informação dentro de seu próprio conceito e com relação a fenômenos específicos". Rodrigues e Crippa (2011, p. 60) também a pontam que emergem muitas perspectivas diferentes que "têm seu ponto de referência ora no objeto, ora no indivíduo, ora na coletividade a qual este indivíduo se insere”. Por sua vez, Tyguel (2011, p. 21-22) questiona se existem diferenças "na forma de mexer com informação e nos tipos de fluxos" de informação quando se assume "os princípios, valores e bandeiras da Economia Solidária". Segundo o autor na ES os fluxos de informação são de fato diferenciados, pois são uma maneira de "fortalecer a transformação social e econômica rumo a uma sociedade sustentável, solidária, justa e diversa". O autor ainda aponta alguns "princípios fundamentais" para atingir os objetivos da ES através da informação: a "cooperação", o "conhecimento livre", a "autogestão" e a "circulação sem concentração" dos fluxos de informação. Quando se coopera os processos relacionados ao processamento e uso da informação ou ao fluxo da informação solidária são distintos de uma organização tradicional, desde a coleta até a disseminação e uso. Ao trabalhar com informação em ES é mister "pensar na informação com base no princípio da cooperação" afirma Tyguel (2011, p. 22) o que transfigura e "interfere especialmente na forma de coleta das informações e nas finalidades de seu uso". Assim, pode-se afirmar que existe uma informação solidária e um fluxo da informação solidária, cuja finalidade é o consumo solidário, um tipo de informação em harmonia com os ideais da ES. A informação solidária é aquela informação que ampara o consumo solidário e estimula atividades econômicas solidárias, que valoriza as pessoas e o meio ambiente e situa-se no contexto de um desenvolvimento econômico sustentável e solidário.

A informação é um "conceito-chave" para a "sociologia", para a "ciência política" e também para a "economia" reconhecem Capurro e Hjorland (2007, p. 173-174), os autores destacam que a "produção, distribuição e acesso à informação estão no centro da nova economia". Conceitos que reforçam a importância da informação no contexto da ES. A informação é descrita por Bramam (apud CAPURRO; HJORLAND, 2007, p. 174) como recurso, mercadoria, percepção de padrões e como "força constitutiva na sociedade". Segundo Capurro (2003) a informação possui os paradigmas "físico", "cognitivo" e "social". Todos os paradigmas da informação emergem quando se discute informação em ES: físico porque existe uma dimensão de gestão da informação e documentação que tem muito a contribuir com a ES através dos arquivos, bibliotecas; cognitivo, pois quando se fala de informação também se fala de conhecimento e educação; social pelo caráter revolucionário e potencial de mudança que a informação contém em si.

Em 2014 ocorreu em Florianópolis a III Conferência Estadual de Economia Solidária (CEES) com o objetivo de somar ideias e propostas à Conferência Nacional de Economia Solidária (CONAES). No encontro nacional foram criados quatro grupos temáticos sobre ES, um deles dedicado exclusivamente à temática da informação e do 
conhecimento. São grupos de trabalho que retratam bem as necessidades de informação na ES, divididos entre os temas: produção, comércio e consumo, financiamento, acesso ao conhecimento e ambiente institucional. (CONAES, 2014, p. 13-14). O grupo temático sobre o "acesso" ao conhecimento é naturalmente ligado à Ciência da Informação e discute, entre outros assuntos, o acesso à informação e conhecimento (pontos fortes e fracos, oportunidades e ameaças), educação, formação profissional, assessoria, disseminação dos ideais da ES e estratégias de potencialização de suas forças intrínsecas. (CONAES, 2014, p. 32). Ao articular conhecimento, "fluxos" de informação e "inteligência”, emerge a questão "incontornável' da educação aponta Arroyo (2008, p. 81), que ainda questiona sobre o "livre fluxo" de informação e a questão a confiança no contexto da cooperação. O estudo dos fluxos de informação através do conhecimento da Ciência da Informação pode elucidar questões relacionadas como a confiança e cooperação, além de propor estratégias para a tomada de decisão coletiva, entre outras soluções.

Através do conhecimento dos problemas de informação reais enfrentados pela ES, especialmente através da produção científica, é possível aproximar o conhecimento da Ciência da Informação do movimento econômico solidário. Assim, os procedimentos metodológicos adotados para alcançar os objetivos propostos e identificar os problemas informacionais na ES são descritos a seguir.

\section{Procedimentos metodológicos}

Para alcançar os objetivos propostos foi realizada pesquisa quantitativa na base SciELO (Scientific Electronic Library Online). A escolha da base tem um significado especial ao abarcar toda a literatura produzida na América Latina, especialmente se observar que a Portaria 2060/2014 do MTE (BRASIL, 2015) destaca que 0 comércio justo e solidário é especialmente importante no "hemisfério Sul".

Foram recuperados 60 artigos revisados por pares com os termos "Economia Solidária" no título. Em seguida foi mensurada a frequência das palavras informação e conhecimento por meio de quatro variáveis: a) contém as palavras informação e conhecimento; b) contém apenas a palavra informação; c) contém apenas a palavra conhecimento; d) não contém as palavras informação e conhecimento.

As variáveis foram associadas a 14 classes de interesse da Ciência da Informação, são elas: 1) busca/recuperação; 2) direito; 3) redes; 4) fluxo de informação, 5) organização/qualidade; 6) sociedade/era; 7) uso da informação; 8) tecnologia; 9) incerteza/desinformação; 10) gestão/processo; 11) fonte de informação; 12) produção/geração; 13) disseminação/compartilhamento/transferência; 14) acesso/obtenção/aquisição. As classes foram elaboradas pelos autores.

Em seguida foi elaborado documento-termo onde foram registradas as frequências das palavras informação e conhecimento na amostra bibliográfica. No documento-termo os artigos foram listados, numerados, registradas as ocorrências das palavras e suas respectivas ligações com as classes de interesse da Ciência da Informação.

A frequência das palavras informação e conhecimento foram classificados como fora de contexto para a pesquisa quando não se enquadravam em nenhuma das 14 classes de interesse da Cl. Os resultados são apresentados a seguir.

\section{Informação e conhecimento na Economia Solidária}

Através dos procedimentos metodológicos adotados foi possível identificar as áreas do conhecimento e os periódicos dominantes na produção e publicação científica sobre ES, os autores mais relevantes e o contexto das ocorrências das palavras informação e conhecimento sob o ponto de vista da Ciência da Informação. As áreas do conhecimento que se mostraram dominantes na produção científica são as Ciências Sociais Aplicadas, seguido das Ciências Humanas e das Ciências da Saúde. Os autores que mais citaram os termos informação e conhecimento dentre os artigos recuperados são: Gomes (2014), Cortegoso (2007), Cortegoso e Cia (2007), Cortegoso e Porto (2007), Kanan (2011), Landriscini (2013), Gaiger (2008, 2012) e Assemburg e Gaiger (2007).

Os periódicos que mais se destacaram são: a) Sociedade Estado do Departamento de Sociologia da Universidade de Brasília (UNB); b) Cadernos Ebape.br da área de Administração da Escola Brasileira de Administração Pública e de Empresas da Fundação Getúlio Vargas (FGV); c) Revista Katálysis do Programa de Pós-Graduação em Serviço Social e do Curso de Graduação de Serviço Social da Universidade Federal de Santa Catarina (UFSC). A frequência dos termos informação e conhecimento, o termo informação aparece isoladamente em $22 \%$ dos artigos, com mais frequência que o termo conhecimento que, por sua vez, aparece 
em $17 \%$ dos artigos. Os termos informação e conhecimento em conjunto incidem em $58 \%$ dos artigos. Os artigos que não citam os termos informação e conhecimento representam apenas $3 \%$ dos textos analisados.

Quanto às interrelações entre as palavras informação e conhecimento e as classes de interesse da Ciência da Informação, apenas quatro classes dentre as 14 apresentaram frequência acima de 10: acesso, produção, disseminação e fontes de informação. Com frequência entre três e nove estão as classes gestão, desinformação, tecnologia e uso. Com frequência de duas ocorrências estão sociedade, organização e fluxo e com a menor frequência dos resultados as classes redes, direito e busca, conforme mostra a Figura 1.

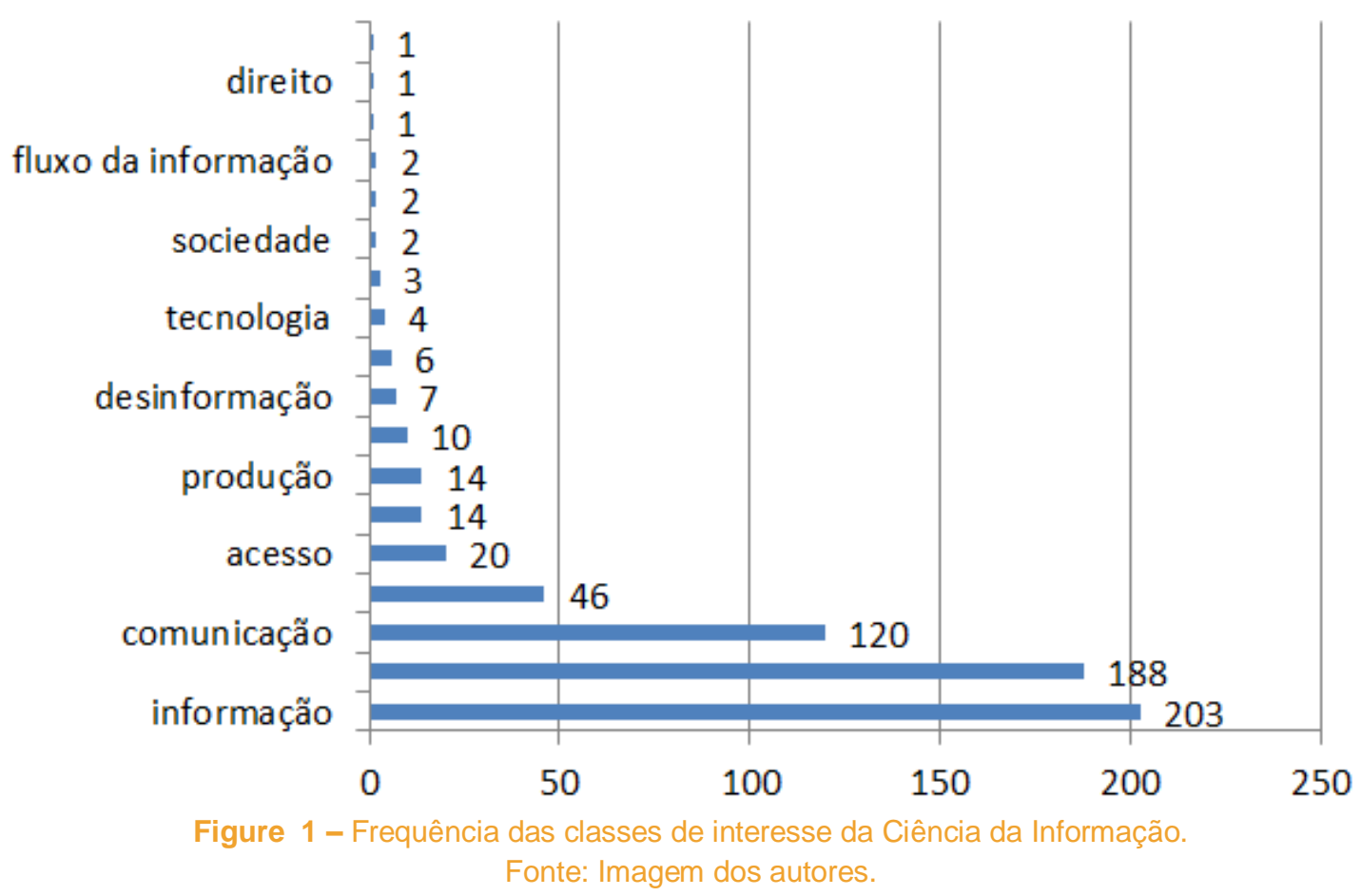

Os resultados mostram a preocupação dos autores que publicam sobre ES com as atividades ligadas à gestão da informação e do conhecimento, em especial o acesso, a disseminação e a produção da informação. Também revelam uma oportunidade para a Ciência da Informação propor soluções através do seu conhecimento, para facilitar o acesso e a disseminação da informação em todas as dimensões do movimento econômico solidário. As necessidades de informação apontadas pelos autores são básicas e estão intrinsecamente ligadas à educação e ao desenvolvimento de competência em informação. Como reconhece Massensini (2011) a "educação é um direito sine qua non a conquista dos direitos civis, políticos e sociais capazes de incluir socialmente um sujeito", promove um ambiente adequado para que as pessoas possam "lutar em pé de igualdade, por uma sociedade mais justa e menos pobre".

Muitos participantes de organizações solidárias possuem pouca formação escolar (por exemplo, os EES que envolvem os catadores de materiais recicláveis) e são elas que mais necessitam das bibliotecas públicas. Onde a ES é mais frágil em termos de informação e conhecimento, o auxílio e o impacto da biblioteca pública pode ser mais forte. São muitas formas com que unidades de informação podem contribuir com o movimento solidário, seja pelas simples aproximação, pela leitura ou empréstimo de livros, treinamento de usuários, entre tantos outros serviços tradicionalmente prestados pelas bibliotecas. Da mesma forma que os profissionais da informação não despertaram para a sua verdadeira responsabilidade social, o movimento econômico solidário também não despertou ainda para o uso que podem fazer das unidades de informação (bibliotecas, arquivos, museus e centros de documentação) e dos seus direitos. Unidades de informação não são citadas na quase totalidade dos artigos analisados. 


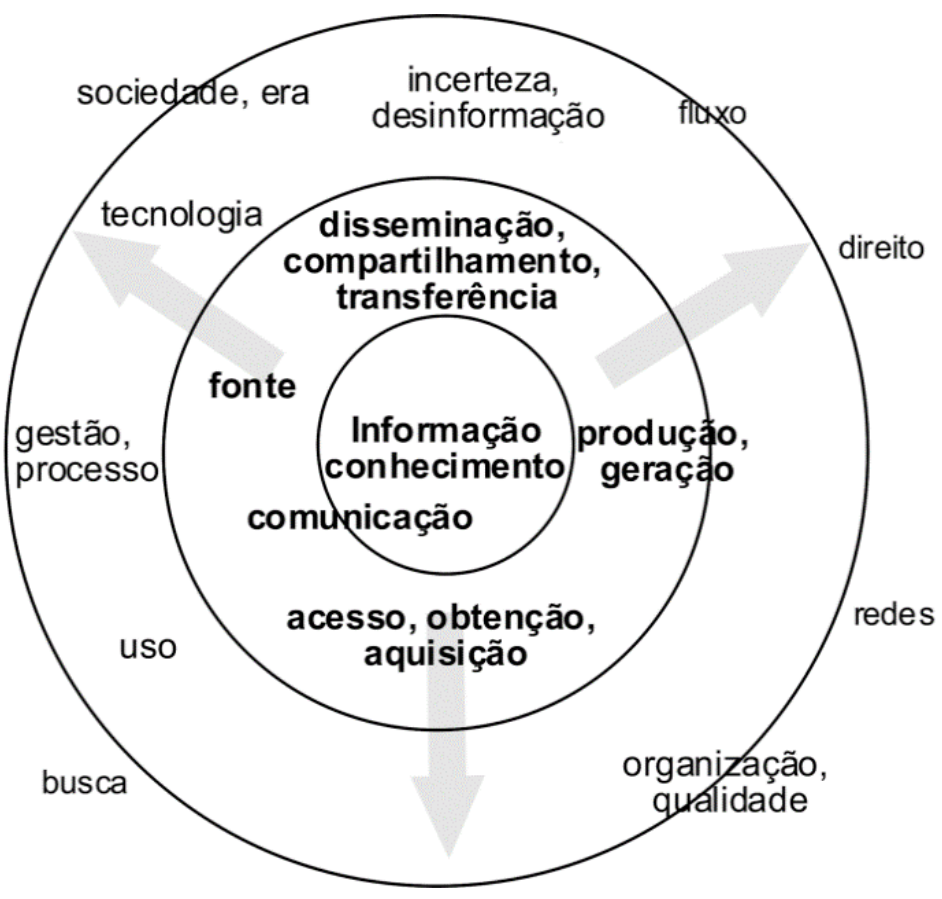

Figure 1 - Relação dos termos informação e conhecimento com as classes de interesse da Ciência da Informação.

Fonte: Imagem dos autores.

A Figura 4 mostra com clareza como estão longe do cerne da informação e o conhecimento, temas como direito à informação, redes, organização, qualidade, pesquisa e recuperação da informação. Palavras que representam realidades distantes, ao passo que o movimento econômico solidário não consegue até o momento atender as necessidades mais básicas como acesso, uso e geração de seus conteúdos, apesar de todos os esforços do Estado que está mais focado em traçar um perfil da ES e levantar dados para a tomada de decisão e planejamento.

As redes de informação ainda não são uma realidade. O SIES mostra que os EES são em grande parte atividades ligadas à agricultura, ao extrativismo e à pesca, empreendimentos rurais que ficam longe das grandes cidades. A inclusão digital no contexto das ES mostra-se como um grande desafio. Como parte da solução para o problema da inclusão digital Massensini (2011) valoriza os mais de 5.700 tele centros existentes no Brasil, como uma forma de "promoção dos direitos e construção da cidadania" e de abrir um "caminho possível" para a inclusão e a "transformação históricossocial". Utilizar criticamente as tecnologias da informação em conjunto com "outras ações" voltadas para a "promoção da igualdade" faz nascer a "cidadania plena" afirma Massensini (2011), uma cidadania ligada a novas transformações "nos sentidos do trabalho". A ampliação dos programas de inclusão digital nas regiões carentes e isoladas permite "novas visões de sociedade" e mais "participação social" reconhece Akhras (2010, p. 19). Pode-se afirmar que a inclusão digital pode fazer crescer a ES de muitas formas e em muitos setores da sociedade, entre participantes ativos e consumidores.

Apesar da preocupação dos autores da área de ES e das abordagens demonstradas nos resultados, temas como acesso, disseminação e produção da informação, se observa que atividades relacionadas à recuperação, organização, uso, gestão e tecnologia da informação são pouco abordadas pelos autores. Evidencia-se uma barreira que deve ser superada para solucionar os demais problemas ligados à informação e conhecimento. É no acesso, disseminação e produção da informação que o conhecimento e a colaboração da Ciência da Informação podem ser mais definitivos.

São muitas as visões e problemas apontados quanto à informação e ao conhecimento. $O$ interesse especial que a ES tem sobre esses temas abre oportunidade para a Ciência de a Informação exercer a sua responsabilidade social nessa importante tendência da economia. Como reflexão final, são apresentadas na Tabela 2 algumas sugestões de ações possíveis para a Ciência da Informação, especialmente aos profissionais das áreas de Biblioteconomia e Arquivologia. 


\begin{tabular}{|l|l|}
\hline \multicolumn{1}{|c|}{ Classe } & \multicolumn{1}{c|}{ Ação } \\
\hline Acesso, obtenção, aquisição & $\begin{array}{l}\text { Aproximação das Bibliotecas Públicas, comunitárias, criação das } \\
\text { próprias bibliotecas, Bibliotecas móveis. Criação de arquivos nos EES, } \\
\text { gestão de documentos. }\end{array}$ \\
\hline Disseminação, compartilhamento & Serviço de disseminação seletiva, Bibliotecas móveis. \\
\hline Produção, geração & Desenvolvimento de competência informacional, inclusão digital. \\
\hline Fonte de informação & Aproximação das bibliotecas, arquivos e museus. \\
\hline Gestão, processo & Gestão da documentação, informação e conhecimento. \\
\hline Incerteza, desinformação & Desenvolvimento de competência informacional. \\
\hline Tecnologia & Inclusão digital, desenvolvimento de competência informacional. \\
\hline Uso da informação & Desenvolvimento de competência informacional \\
\hline Sociedade, era & $\begin{array}{l}\text { Pesquisa científica sobre a ES no contexto da sociedade do } \\
\text { conhecimento. }\end{array}$ \\
\hline Organização, qualidade & Gestão da documentação e informação. \\
\hline Fluxo da informação & Pesquisa científica sobre o fluxo da informação solidária. \\
\hline Redes & $\begin{array}{l}\text { Inclusão digital, pesquisa científica sobre o fluxo da informação } \\
\text { solidária. }\end{array}$ \\
\hline Direito & $\begin{array}{l}\text { Desenvolvimento da dimensão política da competência informacional, } \\
\text { fazer valer a lei de acesso à informação. }\end{array}$ \\
\hline Busca & Desenvolvimento da dimensão técnica da competência informacional. \\
\hline
\end{tabular}

Tabela 1 - Alternativas de ação da Ciência da Informação na Economia Solidária. Fonte: Elaborada pelos autores.

\section{Considerações finais}

A ES diz respeito às atividades econômicas focadas nas pessoas, no meio ambiente e no desenvolvimento sustentável, suas principais referências estão acima do mero lucro e da acumulação de capital. É uma maneira de viver que envolve a integralidade dos trabalhadores e subordina a economia à sua verdadeira finalidade: prover de forma sustentável as bases materiais do desenvolvimento pessoal, social e ambiental. Trata-se de uma tendência da economia que é também um instrumento de transformação social baseado na solidariedade, equidade e democracia direta. Nesse contexto, a informação e o conhecimento possuem um significado especial que se traduz em desafio aos profissionais da informação e à Ciência da Informação.

Mas as unidades de informação e os profissionais da informação, tais como bibliotecários e arquivistas, não são reconhecidos pelos autores que escrevem sobre o tema, e também não despertaram para a ES, o que se traduz pela ausência de pesquisas na área. Assim, é mister uma aproximação e atuação maior por parte dos profissionais, uma aproximação que pode ser realizada de muitas formas, seja pela orientação na organização de arquivos e gestão de documentos, seja no desenvolvimento da competência informacional ou empréstimos de livros. Nesse cenário, as universidades públicas são vetores fundamentais para essa aproximação.

A informação e o conhecimento na ES possuem um caráter especial, são revolucionários ao promover a inclusão social por meio de uma nova economia baseada na solidariedade. Revolucionária porque os EES rompem com a exclusão promovida pelo capital e pelos lucros sem limites das grandes organizações e instituições financeiras.

Empreendimentos de todas as naturezas necessitam de informação na sociedade do conhecimento e para muitos a informação é insumo básico. Mas os EES são o elo mais fraco na luta de gigantes representada pelo mercado, ainda são carentes de informação básica, gestão, apoio, pesquisa, entre outros fatores que limitam a comunicação, a interação e a transferência de conhecimento entre a ES e a sociedade.

Muitos autores apontaram a informação como um problema, da criação ao uso. Palavras como comportamento, consciência, participação e reflexão mostraram-se recorrentes nos textos analisados, a grande frequência de palavras como acesso, busca e compartilhamento de informação evidencia a importância da gestão da informação e do conhecimento, bem como do papel da pesquisa científica em favor da ES. Muitos tipos de informação foram identificados pelos autores como importantes para a ES, desde a informação sobre os EES até a informação comportamental, arquivística, administrativa, sobre produtos e serviços, entre outras, mas destaca-se a informação para a tomada de decisão coletiva e democrática. Também foram identificados os 
autores e as publicações mais relevantes para a Ciência da Informação e realizadas interrelações precisas sobre a questão da informação e do conhecimento em ES, interrelações que evidenciaram que o acesso, uso, disseminação, as fontes de informação, entre outros objetos de estudo da Ciência da Informação, emergiram como carências do movimento econômico solidário.

Constatou-se que muitas carências relacionadas são básicas e devem ser sanadas para que sejam desenvolvidas atividades mais complexas ligadas à informação e ao conhecimento. Observa-se que muitos dos problemas passam necessariamente pela inclusão digital e pela educação, em contrapartida muitas iniciativas de associações, cooperativas e órgãos do governo foram bem sucedidas ao permitir um diagnóstico preciso da ES no Brasil e dispondo grande quantidade de dados aos pesquisadores, instituições e aos EES. Os eventos nacionais e regionais também desempenham papel de destaque nesse universo informacional, integrando, comunicando e disseminando informação e conhecimento relevante. Iniciativas como o Projeto Cirandas (a rede social da ES) e inúmeros outros sítios de internet mostram a importância crescente da informação e do conhecimento como ferramenta estratégica e de gestão em rede, iniciativas que tornam a informação cada vez mais horizontal e solidária.

Os procedimentos metodológicos permitiram conhecer o contexto em que os termos informação e conhecimento são abordados e quais são os problemas e carências da ES que proporciona uma reflexão sobre a atitude dos profissionais da informação, das unidades de informação e das pesquisas que vem sendo realizadas em Ciência da Informação sobre a ES. O desafio da Ciência da Informação não é apenas trazer a ES para dentro das bibliotecas e arquivos, mas também levar a sociedade para dentro da ES e fazer acontecer o consumo solidário, finalidade de todo o processo solidário.

É preciso fortalecer a responsabilidade social dos profissionais da informação através do exercício da profissão comprometido com o desenvolvimento socioeconômico sustentável e com uma economia mais inclusiva e humana. Estudos futuros que tragam o entendimento dos fluxos da informação solidária do papel do profissional da informação e das unidades de informação frente à ES acenam como desafio e oportunidade, cuja contribuição se mostra propícia neste momento histórico que pede mais responsabilidade social para um desenvolvimento econômico solidário e sustentável.

\section{Referências}

AKHRAS, Fabio Nauras. Inclusão digital contextualizada para a inclusão social de comunidades isoladas. Inclusão Social, Brasília, v. 4, n. 1, p. 19-27, 2010.

ALMEIDA JUNIOR, Oswaldo Francisco de. Sociedade e biblioteconomia. São Paulo: APB, 1997. 129 p.

ARAÚJO, Wagner Junqueira de; PINHO, Júlio Afonso de Sá de; CÓRDULA, Flavio Ribeiro. A Instantaneidade da Informação. DataGramaZero, Revista de Informação, v. 16, n. 5, out. 2015. Disponível em: $<$ http://datagramazero.org.br/out15/F | art.htm>. Acesso em: 09/02/2016.

ARROYO, João Cláudio Tupinambá. Cooperação econômica versus competitividade social. Rev.

katálysis, Florianópolis, v. 11, n. 1, jun. 2008. Disponível em: <http://www.scielo.br/scielo.php?script=sci arttext\&pid=S1414$49802008000100007 \&$ lng=en\& $n r m=i s o>$. Acesso em: 05/09/2014.

ARRUDA, Dyego de Oliveira et al. La relación entre la economía solidaria y el desarrollo local: un estudio de caso volcado a los emprendimientos solidarios del turismo brasileño. Estudios y Perspectivas en Turismo. Ciudad Autónoma de Buenos Aires, v. 22, n. 4, ago. 2013. Disponível em: <http://www.scielo.org. ar/scielo.php?script=sci arttext\&pid=S1851$17322013000400007 \& \operatorname{lng}=e s \& n r m=i s o>$. Acesso em: 05/09/2014.

ASSEBURG, Hans Benno; Gaiger, Luiz Inácio. A economia solidária diante das desigualdades. Dados, v. 50, n. 3, p. 499-533, 2007.

AZAMBUJA, Lucas Rodrigues. Os valores da Economia Solidária. Sociologias, n. 21, p. 282-317, 2009.

BRASIL. Ministério do trabalho e emprego. Portaria n. 2.060 de 30/12/2014. Diário Oficial da União, Brasília, DF, 08/01/2015. Disponível em: <http://pesquisa.in.gov.br/imprensa/isp/visualiza/index.jsp?jornal=1\&pagina=53\&data=08/01/2015>. Acesso em: 14/01/2015.

BRASIL. Ministério do trabalho e emprego. Portal do trabalho e emprego. 2014. Disponível em: $<$ http://portal.mte.gov.br/portal-mte>. Acesso em: 06/09/2014. 
BRASIL. Ministério do Trabalho e Emprego. Sistema de Informações em Economia Solidária - SIES. O que é o SIES? 2014b. Disponível em: <http://portal.mte.gov.br/ecosolidaria/sistema-nacional-de-informacoes-em-economia-solidaria>. Acesso em: 09/09/2014.

CAPURRO, R.; HJORLAND, B. O conceito de informação. Perspectivas em Ciência da Informação, Belo Horizonte, v. 12, n.1, p. 148-207, abr. 2007. Disponível em: <http://portaldeperiodicos.eci.ufmg.br/index.php/pci/article/view/54>. Acesso em: 10 abr. 2014.

CAPURRO, R. Epistemologia e Ciência da informação. In: ENCONTRO NACIONAL DE PESQUISA EM CIÊNCIA DA INFORMAÇÃO - ENANCIB, 5., 2003, Belo Horizonte. Anais... Belo Horizonte: Escola de Ciência da Informação da UFMG, 2003.

CASTELLS, Manuel. Redes de indignação e esperança: movimentos sociais na era da internet. Rio de Janeiro: Zahar, 2013.

CONFERÊNCIA NACIONAL DE ECONOMIA SOLIDÁRIA, CONAES, III, 2014, Caderno de orientações metodológicas. Conselho Nacional de Economia Solidária. Secretaria Nacional de Economia Solidária. Ministério do Trabalho e Emprego. Disponível em:

<http://portal.mte.gov.br/data/files/FF8080814373793B0143BB07FCD13A70/Guia\%20Metodol\%C3\%B3gic0\%20-

\%20Gr\%C3\%A1fica.pdf>. Acesso em: 08/09/2014.

CONFERÊNCIA ESTADUAL DE ECONOMIA SOLIDÁRIA, CEES, III, 2014, Secretaria de Estado da Assistência Social, Trabalho e Habitação, Florianópolis/SC, 29 e 30 de maio, 2014.

CORTEGOSO, Ana Lucia. Identificação e descrição de relações comportamentais na economia solidária. Psicologia: Ciência e Profissão, v. 27, n. 2, p. 246-265, 2007.

CORTEGOSO, Ana Lucia; PORTO, Vanessa Camargo Franchini Correa. Comportamento humano e normas de conduta em Economia Solidária: relato de experiência. Psicologia: Teoria e Pesquisa, v. 23, n. 4, p. 449-456, 2007.

CORTEGOSO, Ana Lúcia; Cia, Fabiana. Condutas de mediadores em processos de decisão coletiva como condição para uma educação emancipatória na Economia Solidária. Psicologia e Sociedade, Porto Alegre, v. 19, n. 2, ago. 2007. Disponível em: $<$ http://www.scielo.br/scielo.php?script=sci arttext\&pid=S0102-71822007000200014\&lng=en\&nrm=iso>. Acesso em: 05/09/2014

FONSECA, Juliana Soares da; Garcia, Joana Coeli Ribeiro. Responsabilidade ética e social do profissional da informação. Biblionline, João Pessoa, v. 5, n. 1, jan./abr. 2009.

FREIRE, I. M. Da construção do conhecimento científico à responsabilidade social da Ciência da Informação. Informação \& Sociedade: estudos, João Pessoa, v. 12, n. 1, 2002. Disponível em: <http://www.ies.ufpb.br/ojs2/index.php/ies/article/ view/ 158/152>. Acesso em: 02 ago. 2014.

GAIGER, Luiz Inácio Germany. A economia solidária e o valor das relações sociais vinculantes. Revista Katálysis, Florianópolis, v. 11, n. 1, jun., 2008. Disponível em: <http://www.scielo.br/scielo.php?script=sci arttext\&pid=S1414$49802008000100002 \& \operatorname{lng}=e n \& n r m=i s 0>$. Acesso em: 05/09/2014.

GAIGER, Luiz Inácio Germany. Por um olhar inverso: prismas e questões de pesquisa sobre a economia solidária. Sociedade e Estado, v. 27, n.2, p. 313-335, 2012.

GANDRA, Tatiane Krempser; DUARTE, Adriana Bogliolo Sirihal. Usuários da informação sob a perspectiva fenomenológica: revisão de literatura e proposta de postura metodológica de pesquisa. Informação \& Sociedade: Estudos, João Pessoa, v. 22, n. 2, 2012. Disponível em: <http://www. brapci.ufpr.br/documento. php?dd0=0000012396\&dd1=6a31e >. Acesso em: $09 / 02 / 2016$.

GOMES, Fábio. Uma aproximação entre pragmática universal e economia solidária: o caso de Catende. Cadernos EBAPE.BR, v. 12, p. 416-441, 2014.

GUINCHAT, Claire; Menou, Michel. A pesquisa em ciências e técnicas da informação. In: Introdução geral às ciências e técnicas da informação e documentação. 2. ed., Brasília: IBICT, 1994.

ICA International Co-operative Alliance. Co-operative identity, values \& principles. Disponível em: <http://ica.coop/en/whatsco-op/co-operative-identity-values-principles>. Acesso em: 10/01/2015.

KANAN, Lilia Aparecida. Consumo sustentável \& economia solidária: alguns conceitos e contribuições da Psicologia. Fractal Revista de Psicologia, Rio de Janeiro, v. 23, n. 3, dez., 2011. Disponível em: <http://www.scielo.br/scielo.php?script=sci arttext\&pid=S1984-02922011000300011\&lng=en\&nrm=iso>. Acesso em: 05/09/ 2014.

KUYVEN, Patricia Sorgatto; KAPPES, Sylvio Antônio. II Mapeamento da Economia Solidária Região Sul, Resultados do segundo Mapeamento Nacional. Coordenação: Luiz Inácio Gaiger. São Leopoldo, Brasil, 2013. Disponível em: 
$<$ http://sies.ecosol.org.br/images/resultado/ii-mapeamento-da-economia-solidaria-regiao-sul-cartilha-informativa.pdf>. Acesso em: 08/20/2014.

LANDRISCINI, Graciela. Economía social y solidaria en la patagonia norte: Experiencias, saberes y prácticas. Casos y reflexiones. Revista Pilquen, v. 16, n. 2, 2013.

LE COADIC, Yves-François. A ciência da informação. Brasília, DF: Briquet de Lemos, 1996.

MASSENSINI, Rogério Luís. Inclusão digital: sob a ótica da cidadania plena. DataGramaZero, Rio de Janeiro, v. 12, n. 2, abr. 2011. Disponível em: <http://www.dgz.org.br/abr11/Art 06.htm>. Acesso em: 10/01/2015.

NAGEM, Fernanda Abreu; SILVA, Sandro Pereira. Institucionalização e execução das políticas públicas de economia solidária no Brasil. Revista de Sociologia e Política, Curitiba, v. 21, n. 46, jun. 2013. Disponível em:

<http://www.scielo.br/scielo.php?script=sci arttext\&pid=S0104-44782013000200010\&lng=en\&nrm=iso>. Acesso em: 05/09/2014

RODRIGUES, Bruno César; CRIPPA, Giulia. A recuperação da informação e o conceito de informação: o que é relevante em mediação cultural?. Perspectivas em Ciência da Informação, Belo Horizonte, v. 16, n. 1, p. 45-64, jan./abr. 2011. Disponível em: <http://www.brapci.ufpr.br/documento.php?dd0=0000009880\&dd1=91887>. Acesso em: 09/02/2016.

SARACEVIC, Tefko. Ciência da informação: origem, evolução e relações. Perspectivas em Ciência da Informação, Belo Horizonte, v. 1, n. 1, p. 41-62, jan./jun. 1996.

SILVA, Marcelo Kunrath; OLIVEIRA, Gerson de Lima. Solidariedade assimétrica: capital social, hierarquia e êxito em um empreendimento de "economia solidária". Revista Katálysis, Florianópolis , v. 12, n. 1, jun. 2009. Disponível em: <http://www.scielo.br/scielo.php?script=sci arttext\&pid=S1414-49802009000100008\&lng=en\&nrm=iso>. Acesso em: 05/09/2014

SINGER, Paul. Desenvolvimento capitalista e desenvolvimento solidário. Estudos Avançados, v. 18, n. 51, p. 7-22, 2004.

TYGUEL, Daniel. Fluxos e informações na Economia Solidária: um novo olhar sobre a prática. Instituto Brasileiro de Análises Sociais e Econômicas (IBASE), Rio de Janeiro, 2011. Disponível em:

<http://inspirebr.com.br/uploads/midiateca/cfc0b6489131c4e7e82f1c4e3129de29.pdf>. Acesso em: 09/02/2016. 


\section{Dados dos autores}

\section{Angel Freddy Godoy Viera}

Possui mestrado em Ciências da Computação pela Universidade Federal de Santa Catarina (1996) e doutorado em Engenharia de Produção pela Universidade Federal de Santa Catarina (2001). Atualmente é Professor Associado III da Universidade Federal de Santa Catarina. Tem experiência na área de Ciência da Informação, com ênfase em Recuperação Inteligente de Informação, atuando principalmente nos seguintes temas: recuperação da informação, aprendizagem de máquina, deep learning, mineração de texto, mineração de dados e processamento de linguagem natural.

godoy@cin.ufsc.br

\section{Fabricio Foresti}

Graduado em bacharelado em biblioteconomia pela Universidade Federal de Santa Catarina (2006) com experiência na área de Ciência da Informação, Arquivologia e Biblioteconomia. É programador e web designer. Possui trabalhos em gestão da informação e conhecimento. Atualmente cursa Mestrado em Ciência da Informação pela UFSC.

fabricio.foresti@ufsc.br

\section{Viviane da Rosa}

Possui graduação em Ciências Sociais pela Pontifícia Universidade Católica do Rio Grande do Sul(2000) e mestrado em Sociologia Política pela Universidade Federal de Santa Catarina(2003). Atualmente é Efetivo da Secretaria de Estado da Assistência Social, Trabalho e Habitação de SC..

vivialuarosa@gmail.com

Recibido - Received: 2015-11-23

Aceitado - Accepted: 2016-02-19

\section{$(\mathrm{cc})$ EY}

This work is licensed under a Creative Commons Attribution 4.0

United States License.

\section{ULIS D-Sulf}

This journal is published by the University Library System of the University of Pittsburgh as part of its D-Scribe Digital Publishing Program and is cosponsored by the University of Pittsburgh Press. 